\title{
Application of ESCO phytosystem based on narrow-band light-emitting diodes for growing cucumbers under photoculture conditions
}

\author{
Nina Apaeva*, Lubov Kudryashova, and Sergey Manishkin \\ Mari State University, 424000, Lenin Square 1, Republic of Mari El, Yoshkar-Ola, \\ Russian Federation
}

\begin{abstract}
The article deals with the study of photomorphogenesis of different cucumber varieties under light culture conditions. Studies were carried out under laboratory conditions using an experimental phytosystem ESCO based on narrow-band light-emitting diodes, which is equipped with a microcontroller. The microcontroller controls the supplementary light modes. Studies were conducted to develop recommendations for selecting and controlling the spectral composition of light optimal for the life cycle of plants. The aim of our research is to study photomorphogenesis of different cucumber varieties under light-culture conditions using an experimental ESCO phytosystem based on narrow-band light-emitting diodes equipped with a microcontroller that controls the supplementary light modes. Four cucumber hybrids were used to test the ESCO phytosystem. Phytolamps were placed at the height of $1 \mathrm{~m}$ in the beginning, then at the height of $1.2 \mathrm{~m}$. Every day we recorded the growth of shoot length, establishment of generative organs (flowers), we recorded the date of flowering and fruit formation. Conditions of humidity, nutrient and air regimes corresponded to biological requirements of growth and development of cucumber plants. Studies have shown that laying of generative organs of cucumber with additional lighting with narrow-band light emitting diodes is good. Female flowers appeared 7-14 days earlier in $\mathrm{BV} 700+\mathrm{RV} 350+\mathrm{BF} 350+\mathrm{FRF} 350$ regime than in plants grown under natural light. The RV light regime had a significant effect on the increase in plant height. Determination of chlorophyll content showed its optimal amount and depended on the varietal characteristics of plants. The best supplementary light mode was BV700+RV350+ BF350+FRF350 during the cultivation of seedlings of different cucumber hybrids. Mode change all to 500 after planting in the ground.
\end{abstract}

\section{Introduction}

\footnotetext{
* Corresponding author: apaevanina@mail.ru
} 
Photoculture of plants is the cultivation of plants using artificial irradiation. Photoculture of plants is carried out entirely with artificial light, or in addition to sunlight; the latter is used in greenhouses to lengthen the short day and increase the intensity of plant illumination in the winter months [12]. The spectral composition of radiation, the intensity of physiological radiation, as well as the day length for photoculture are essential [18]. Intensive photoculture contributes to the practical realization of the potential productivity of plants laid down genetically [7].

Cultivation of vegetable plants in photoculture is a major element of production technology in modern greenhouse complexes [5]. Low-pressure sodium lamps DNAT and mercury lamps are traditionally used for additional lighting of vegetable crops in greenhouse combines, which have maximum absorption in the region of 550-600 and 450 $\mathrm{nm}$. The problem of using LED lights to optimize the light regime of plants is currently relevant. This problem has a research nature. Scientists are studying the effect of LED lights on yield, biochemical composition and efficiency of vegetable production [12].

The use of modern light sources as LED irradiators allows a sharp reduction in energy costs for growing plants due to the high light output, long working life and the ability to regulate the spectrum of radiation. LEDs can serve as additional irradiators or completely replace traditional light sources when growing plants [13, 17]. Positive results were obtained on various crops (Chinese cabbage, garden strawberry, potato, basil) [1, 2, 14] when using LEDs. I. A. Kungs, I. A. Ugreninov argue that the introduction of LED lighting in greenhouses is promising from an economic point of view [11].

In recent years, scientists are paying more and more attention to the cultivation of vegetable crops under photoculture conditions. Photoculture is especially relevant in the northern regions of Russia. It allows you to get a harvest of vegetables in winter time. The study of the problem of growing vegetables under photoculture conditions is reflected in the works of domestic and foreign scientists $[15,16,19,3,6]$.

A.E. Kohler and R.G. Lopez [10] investigated the effect of light treatment on the appearance of buds and flowering of ornamental crops. They found that the inclusion of FR radiation via LED SL accelerates flowering time.

Scientists studied the effect of light intensity, light spectrum and wavelength of LEDs on the quality of vegetable crops, in particular, broccoli, carrots, microgreens (microgreens) $[4,8,9,20]$.

The aim of our research was to study photomorphogenesis of different cucumber varieties under photoculture conditions using an experimental ESCO phytosystem based on narrow-band light-emitting diodes equipped with a microcontroller that controls the supplementary light modes.

\section{Methods}

The cultivation of cucumbers in photoculture was carried out in the biolaboratory of Mari State University. The environment in the laboratory was appropriate for such studies. The laboratory has no window openings, a part of the laboratory was separated by black film for installation. Peat mats were laid on 4 tables (size $2.6 \times 1.2 \mathrm{~m}$ ) and drainage drains were installed. Experimental phytosystem ESCO based on narrow-band light-emitting diodes was mounted above the tables (Fig. 1), equipped with a microcontroller that controls the supplementary lighting modes. The height of the lamps is $1 \mathrm{~m}$, with a subsequent change in height to $1.2 \mathrm{~m}$. 


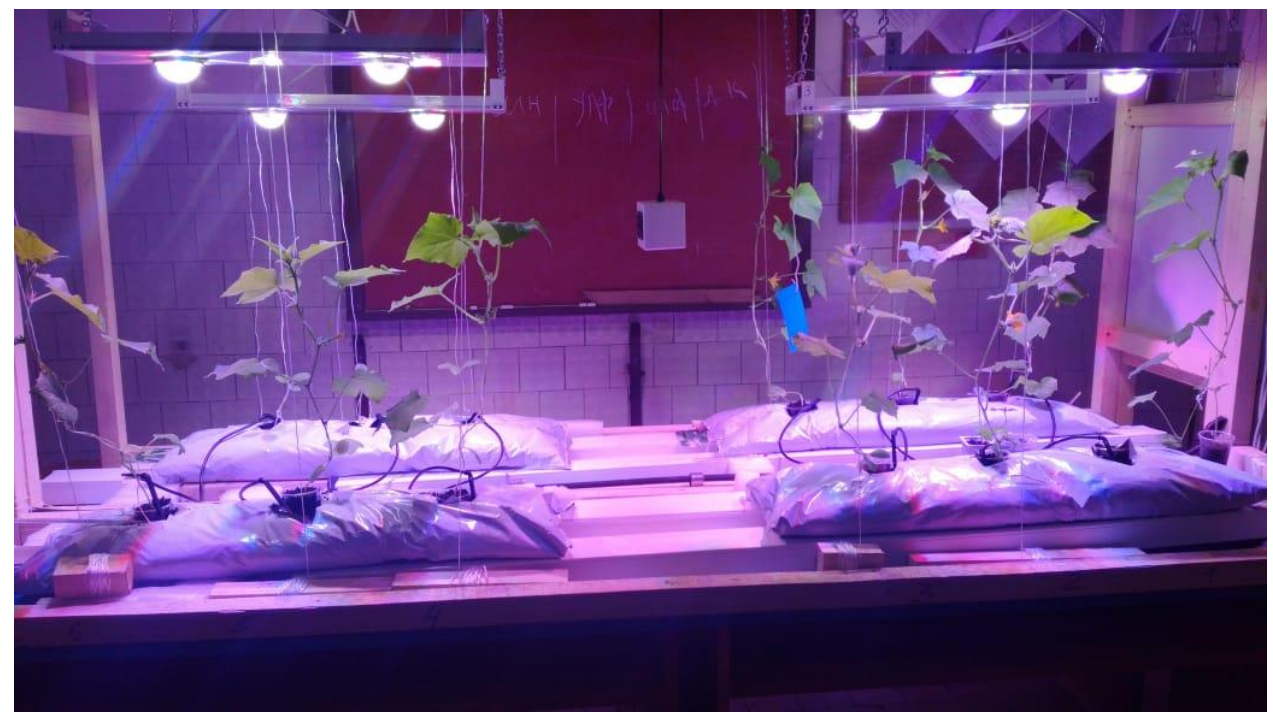

Fig. 1. The installation after planting.

We tested four cucumber hybrids for growing in photoculture: Real Colonel F1, RMT F1, Cheboksarets F1, Vyatsky F1. Cucumber seeds were planted in $200 \mathrm{ml}$ cups on February 6, where they were grown in natural light until March 12. Then the seedlings were planted in peat mats of 3 plants each (mat length is 1), width is $20 \mathrm{~cm}$.Drip heads were brought to water each plant (drip irrigation Beetle). Cucumbers were fertilized with solution A (content of N-8\%, P2O5-6\%, K2O-28\%, Mg-3\%, Zn-0,01\%, Cu-0,01\%, Mn$0,1 \%$, Mo- $0,001 \%$, B- $0,01 \%$ ). Distilled water was used for feeding and watering. Fertilizing was carried out by Dissolverin A fertilizer during cucumber growing period. Feeding was carried out 5 times in the first month of cucumber growing, then every day. Iron chelate was used 2 times at the beginning of vegetation. Fertilizer Agris Universal was used once.

Analysis of the extract from the peat mat showed that $\mathrm{pH}$ was 6.7 , the content of exchangeable potassium was $0.16 \mathrm{~g} / \mathrm{l}$, mobile phosphorus was $0.08 \mathrm{mg} / \mathrm{l}$, and traces of nitrates.

Every day we recorded the growth of shoot length, the establishment of generative organs (flowers), we recorded the date of flowering and fruit formation. Yield was counted by weighing each fruit on electronic scales. Chlorophyll was determined on a spectrophotometer. Nitrates were determined by ionometric method on a nitrate meter and a portable nitrate meter. Light intensity measurements were made on a spectrophotometer version 3.0 for TKA-VD.

The average air temperature was $18-23^{\circ} \mathrm{C}$ in the morning in March and was $21-24^{\circ} \mathrm{C}$ in the evening. Morning and evening air temperatures were higher in April than in March, ranging from 20 to $26^{\circ} \mathrm{C}$ in the morning and 22 to $26^{\circ} \mathrm{C}$ in the evening. We found that when the lamp was turned off, the air temperature decreased by 2 to 3 degrees. Ground temperature varied between $20-23^{\circ} \mathrm{C}$ in March. At night, the ground temperature decreased by $1-2^{\circ} \mathrm{C}$. Ground temperature was higher (average was $24^{\circ} \mathrm{C}$ ) in April. Humidity ranged between $50-80 \%$ in March, and between $60-90 \%$ in April. Carbon dioxide is required by plants for the daytime phase of photosynthesis. Concentration of carbon dioxide was recorded by a sensor. Microclimate was satisfactory in the cucumber growing room. 


\section{Results}

Adaptation to the new lighting conditions occurred in March, so the average daily growth was small in all hybrids planted with seedlings grown in natural light.

In April, after adaptation, growth of cucumber plants increased and was from 2 to 14.5 $\mathrm{cm}$ for the hybrid Real Colonel, it was from 2 to $8.7 \mathrm{~cm}$ for RMT and it was from 3 to 10.5 $\mathrm{cm}$ for Cheboksarets (Fig. 2).

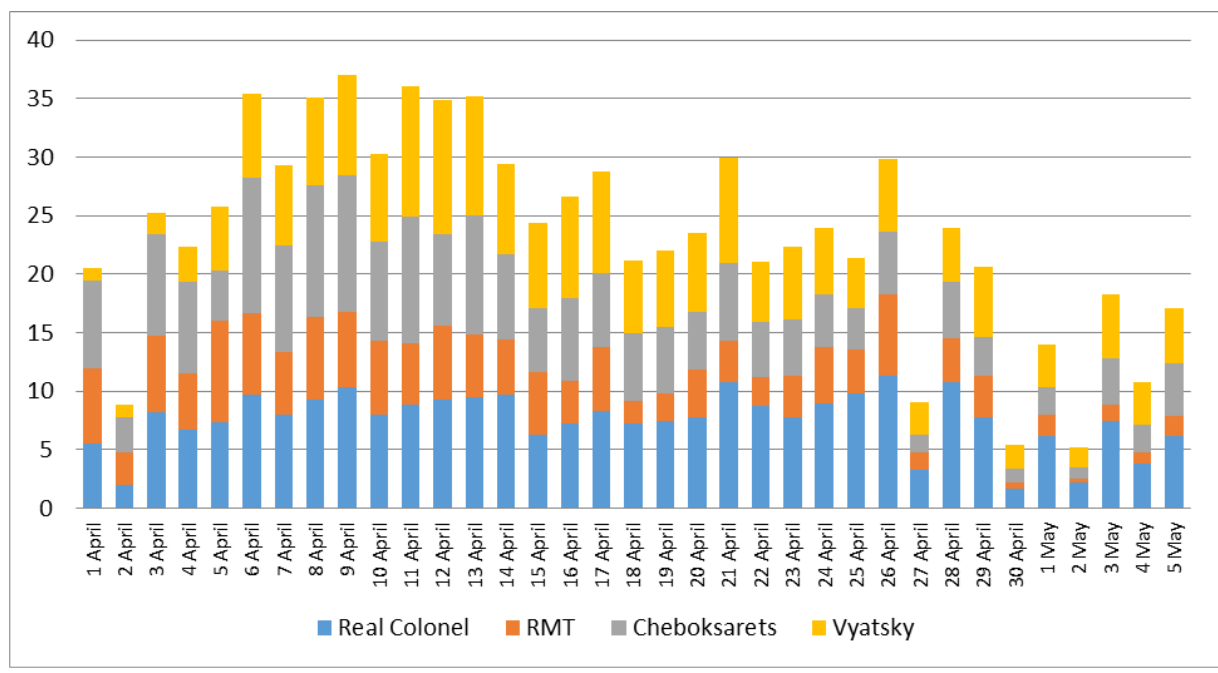

Fig. 2. Average daily growth of cucumber shoot length in April and May, cm.

Sprouts have varietal characteristics depending on the supplementary light mode. The data are presented in Table 1.

Table 1. Dependence of average daily growth of hybrids on the supplementary light mode, $\mathrm{cm}$.

\begin{tabular}{|l|c|c|c|c|}
\hline \multicolumn{1}{|c|}{ Hybrids } & $\begin{array}{c}\text { BV700+ } \\
\text { FRF700 }\end{array}$ & $\begin{array}{c}\text { BV700+ } \\
\text { BF350+FRF350 }\end{array}$ & $\begin{array}{c}\text { BV700+RV350+ } \\
\text { BF350+FRF350 }\end{array}$ & $\begin{array}{c}\text { BV500+RV500+ } \\
\text { BF500+FRF500 }\end{array}$ \\
\hline Real Colonel & 2,0 & 1,8 & 6,2 & 8,1 \\
\hline RMT & 1,7 & 1,6 & 5,2 & 3,9 \\
\hline Cheboksarets & 1,9 & 2,6 & 7,4 & 5,6 \\
\hline Vyatsky & - & - & 3,7 & 6,8 \\
\hline
\end{tabular}

The highest average daily growth was observed in the mode all to 500 on hybrid Vyatsky, it was was $6.8 \mathrm{~cm}$, with the mode BV700 + RV350 + BF350 + FRF350 highest growth was observed on hybrid Cheboksarets, it was $7.4 \mathrm{~cm}$.

Table 2. Total cucumber stems length growth on April 30, cm.

\begin{tabular}{|c|c|c|}
\hline \multirow{2}{*}{ Hybrids } & Plant numbers & Stems length, cm \\
\hline \multirow{2}{*}{ Real Colonel } & 1 & 294,5 \\
\cline { 2 - 3 } & 2 & 302,5 \\
\hline
\end{tabular}




\begin{tabular}{|c|c|c|}
\hline \multirow{4}{*}{ RMT } & 3 & 326 \\
\cline { 2 - 3 } & in average & 307,8 \\
\cline { 2 - 3 } & 1 & 208 \\
\cline { 2 - 3 } & 2 & 103 \\
\cline { 2 - 3 } & 3 & 199 \\
\hline \multirow{4}{*}{ Cheboksarets } & in average & 170 \\
\cline { 2 - 3 } & 1 & 279,5 \\
\cline { 2 - 3 } & 2 & 318 \\
\cline { 2 - 3 } & 3 & 216 \\
\hline \multirow{5}{*}{ Vyatsky } & in average & 271,2 \\
\cline { 2 - 3 } & 1 & 283 \\
\cline { 2 - 3 } & 2 & 248 \\
\cline { 2 - 3 } & 3 & 242,5 \\
\hline
\end{tabular}

Cucumber stems grew from 170 to $307.8 \mathrm{~cm}$ depending on the hybrid, as seen in Table 2, during the period from March 12 to May 5. Variety differences in total stems length are revealed. RMT F1 has more restrained growth. This hybrid has short internodes, smaller leaves, superbunchy type, 5 to 8 ovaries are formed on one node.

The Real Colonel F1 has the strongest stem growth. Its length of one plant was 294.5 $\mathrm{cm}$, the second was $302.5 \mathrm{~cm}$ and the third was $326 \mathrm{~cm}$. The middle plant, which was between two bulbs, had a shorter length, due to shorter internodes.

Table 3. Scheme of lamp arrangement and total stems length of cucumber hybrids.

\begin{tabular}{|c|c|c|c|c|c|}
\hline \multicolumn{3}{|c|}{ Vyatsky $F_{1}$} & \multicolumn{3}{|c|}{ Cheboksarets $F_{1}$} \\
\hline $242,5 \mathrm{~cm}$ & $248 \mathrm{~cm}$ & $283 \mathrm{~cm}$ & $216 \mathrm{~cm}$ & $318 \mathrm{~cm}$ & $279,5 \mathrm{~cm}$ \\
\hline \multicolumn{3}{|c|}{ RMT F $F_{1}$} & \multicolumn{3}{|c|}{ Real Colonel $F_{1}$} \\
\hline $199 \mathrm{~cm}$ & $103 \mathrm{~cm}$ & $208 \mathrm{~cm}$ & $326 \mathrm{~cm}$ & $302,5 \mathrm{~cm}$ & $294,5 \mathrm{~cm}$ \\
\hline
\end{tabular}

Cheboksarets F1 ranked second in stem length $(216-318 \mathrm{~cm})$. The plant in the middle had a greater length compared to the plants under the lamps.

One conclusion cannot be made for all four cucumber hybrids, the varietal growth peculiarities are affecting. Plants had greater length under white lamps on hybrids Real Colonel, RMT and Vyatsky, and smaller length plants had under green lamps, middle plants of Vyatsky and Real Colonel had intermediate length. Everything was different in the Cheboksarets hybrid.

The number of internodes changes depending on the hybrid and being under a certain lamp color (Table 4).

Table 4. Layout of lamps and number of internodes on a cucumber plant.

\begin{tabular}{|c|c|c|c|c|c|}
\hline \multicolumn{3}{|c|}{ Vyatsky F 1} & \multicolumn{3}{c|}{ Cheboksarets F 1} \\
\hline 32 & 31 & 31 & $\times$ & $\times$ & $\times$ \\
\hline \multicolumn{3}{|c|}{ RMT F 1} & \multicolumn{3}{c|}{ Real Colonel F } \\
\hline 45 & 48 & 61 & 44 & 21 & 45 \\
\hline
\end{tabular}


Note: $\times$ - did not define.

Under the white lamps, the length was greater than under the green lamps. Plants in the center had a shorter length in all hybrids.

Supplementary light mode was turned on at BV700+FRF700 after planting the seedlings for the period from March 13 to 18. On March 18, female ovaries were noted on the plants in the 4th node.

On March 20, the supplementary light mode was changed to BV700+BF350+FRF350. It is necessary to increase the vegetative mass to increase photosynthesis and growth of ovaries with the appearance of ovaries.

On March 21, a female flower bloomed on the 4th node. A female flower was found on two plants on the 5 th node. Male flowers were removed.

On March 25, the supplementary light mode was changed to BV700+RV350+BF350+FRF350. Female flowers were opened at 5-6 nodes. Lateral shoots begin to grow actively from the fourth node.

Determination of chlorophyll content in leaves of cucumber hybrids was carried out. The data are shown in Table 5.

Table 5. Chlorophyll content in cucumber leaves, $\mathrm{mg} / \mathrm{g}$.

\begin{tabular}{|l|c|c|c|c|}
\hline \multirow{2}{*}{ Hybrids } & \multicolumn{4}{|c|}{ Chlorophyll } \\
\cline { 2 - 5 } & $\mathbf{a}$ & $\mathbf{b}$ & $\mathbf{a}+\mathbf{b}$ & $\mathbf{a} / \mathbf{b}$ \\
\hline Real Colonel & 1,34 & 0,54 & 1,88 & 2,49 \\
\hline RMT & 1,7 & 0,65 & 2,38 & 2,5 \\
\hline Cheboksarets & 1,3 & 0,54 & 1,84 & 2,4 \\
\hline
\end{tabular}

Chlorophyll content in leaves is optimal under photoculture conditions. RMT hybrid had higher content of chlorophyll a and b. Chlorophyll was not defined on hybrid Vyatsky.

On April 10, the supplementary light mode was changed to BV500+RV500+BF500+FRF500. On April 11, we harvested the first fruits of $58 \mathrm{~g}, 52 \mathrm{~g}$, $70 \mathrm{~g}$ and $45 \mathrm{~g}$, for a total of $215 \mathrm{~g}$ per bush. The content of nitrates was $7 \mathrm{mg} / \mathrm{kg}$ in the fruits. During the period from March 12 to May 13, more fruits were harvested from the plants that were in the middle. The second plant of the Real colonel hybrid yielded $216 \mathrm{~g}$ of fruits, while the first and third plants did not grow any fruit. The hybrid RMT yielded $652 \mathrm{~g}$ from the second plant, it yielded $322 \mathrm{~g}$ from the first plant, and it yielded $124 \mathrm{~g}$ from the third. The hybrid Cheboksarets yielded $392 \mathrm{~g}$ of fruits from the second plant, it yielded 308 $\mathrm{g}$ from the first plant, and it yielded $226 \mathrm{~g}$ from the third plant.

The illumination of all plants in the BV700+FRF700 mode was the same. The location of the plants did not matter.

There is a dependence of illumination on the position of plants in BV700+RV350+BF350+FRF350 mode. The central plants located between the lamps had higher illumination than in the extreme ones (Table 6).

Table 6. Influence of plant location under lamps on illumination at BV700+RV350+BF350+FRF350 mode and light intensity. 


\begin{tabular}{|c|c|c|c|c|c|}
\hline \multicolumn{3}{|c|}{ Vyatsky $F_{1}$} & \multicolumn{3}{|c|}{ Cheboksarets $F_{1}$} \\
\hline 6887,7 & 9231,9 & 7906,3 & 5332,7 & 7771,3 & 6571,2 \\
\hline $\begin{array}{c}0,62 / 1 / 0,91 / 0,9 \\
3\end{array}$ & $\begin{array}{c}0,55 / 0,92 / 1 / \\
0,51\end{array}$ & $\begin{array}{c}0,25 / 0,63 / 1 / 0 \\
, 23\end{array}$ & $\begin{array}{c}0,62 / 0,95 / 0,95 / \\
1\end{array}$ & $\begin{array}{c}0,59 / 0,9 / 1 / \\
0,6\end{array}$ & $\begin{array}{c}0,49 / 0,81 / 1 / 0 \\
, 45\end{array}$ \\
\hline \multicolumn{3}{|c|}{ RMT F 1} & \multicolumn{3}{|c|}{ Real Colonel $F_{1}$} \\
\hline 6476,6 & 7643,7 & 4005,9 & 5368 & 7380 & 3533,8 \\
\hline $0,23 / 0,9 / 1 / 0,17$ & $\begin{array}{c}0,35 / 0,95 / 1 / \\
0,28\end{array}$ & $\begin{array}{c}0,56 / 0,45 / 0,5 \\
/ 1\end{array}$ & $0,2 / 0,51 / 1 / 0,05$ & $\begin{array}{c}0,48 / 0,85 / 1 \\
/ 0,4\end{array}$ & $\begin{array}{c}0,45 / 0,68 / 0,7 \\
2 / 1\end{array}$ \\
\hline
\end{tabular}

Note: * first number is intensity $420 \mathrm{~nm}$, the second is $450 \mathrm{~nm}$, the third is $660 \mathrm{~nm}$, the fourth is $750 \mathrm{~nm}$

Further measurements were carried out only on plants of hybrid Cheboksarets to define how the light irradiance and light intensity changes depending on the supplementary light modes, the data are shown in Table 7.

Table 7. Light intensity readings under LED lamps in different supplementary light modes.

\begin{tabular}{|c|c|c|c|c|c|}
\hline \multirow{2}{*}{ Plant number } & \multicolumn{4}{|c|}{ Intensity } & \multirow{2}{*}{$\begin{array}{l}\text { Illumination, } \\
\text { lux }\end{array}$} \\
\hline & $420 \mathrm{~nm}$ & $450 \mathrm{~nm}$ & $660 \mathrm{~nm}$ & $750 \mathrm{~nm}$ & \\
\hline \multicolumn{6}{|c|}{ mode BV500+RV500+BF500+FRF500 } \\
\hline 1 & 0,42 & 0,51 & 1 & 0,41 & 6561,4 \\
\hline 2 & 0,5 & 0,6 & 1 & 0,68 & 7803,3 \\
\hline 3 & 0,51 & 0,6 & 1 & 0,85 & 6459,8 \\
\hline \multicolumn{6}{|c|}{ mode BV500+RV700+BF700+FRF500 } \\
\hline 1 & 0,5 & 0,5 & 1 & 0,45 & 6440,9 \\
\hline 2 & 0,5 & 0,51 & 1 & 0,46 & 6402,8 \\
\hline 3 & 0,56 & 0,52 & 1 & 0,5 & 6433 \\
\hline \multicolumn{6}{|c|}{ mode BV700+RV350+BF500+FRF700 } \\
\hline 1 & 0,65 & 0,86 & 1 & 0,71 & 6756,3 \\
\hline 2 & 0,75 & 0,95 & 1 & 0,95 & 7187,6 \\
\hline 3 & 0,6 & 0,72 & 0,78 & 1 & 5895,5 \\
\hline
\end{tabular}




\begin{tabular}{|c|c|c|c|c|c|}
\hline \multicolumn{7}{|c|}{ mode BV700+RV700+BF500+FRF500 } \\
\hline 1 & 0,5 & 0,53 & 1 & 0,45 & 6756,3 \\
\hline 2 & 0,5 & 0,66 & 1 & 0,46 & 6688,7 \\
\hline 3 & 0,45 & 0,51 & 1 & 0,55 & 6245,3 \\
\hline \multicolumn{7}{|c|}{ mode BV500+RV500+BF700+FRF700 } \\
\hline 1 & 0,5 & 0,55 & 1 & 0,51 & 7076,5 \\
\hline 2 & 0,6 & 0,63 & 1 & 0,69 & 7279,6 \\
\hline 3 & 0,65 & 0,7 & 0,95 & 1 & 5843,3 \\
\hline
\end{tabular}

The best illumination was observed for plants located in the center. And better illumination was on the first plant only in BV500+RV700+BF700+FRF500 and BV700+RV700+BF500+FRF500 modes.

The average electric power consumption for the period of 10 hours of auxiliary light was $5.5 \mathrm{~kW}$ in the BV700+ FRF700 operating mode, it was $5 \mathrm{~kW}$ in the BV700+ BF350+FRF350 operating mode, it was $6.9 \mathrm{~kW}$ in the BV700+RV350+ BF350+FRF350 operating mode and it was $7 \mathrm{~kW}$ in the BV500+RV500+ BF500+FRF500 operating mode.

Overall, from March 12 to April 30, power consumption was $433 \mathrm{~kW}$, with an average consumption of $9 \mathrm{~kW}$ per day during 10 hours of supplementary lighting mode.

\section{Discussion}

Good laying of generative organs occurs when growing cucumber under conditions of additional lighting with narrow-band light-emitting diodes. There are more female flowers formed under these conditions. Flowering of cucumbers begins 7-14 days earlier compared to growing them under natural light.

The length of the stems is reduced under supplementary lighting with the ESCO phytosystem based on narrow-band light-emitting diodes, in contrast to growing cucumbers under natural light. Cucumbers produced more fruit when grown under white light lamps. Cucumbers produced less when grown under lamps with green light.

Determination of chlorophyll content showed its optimal amount. Variety differences occurred. The highest chlorophyll $\mathrm{a}+\mathrm{b}$ content was in hybrid RMT $-2.38 \mathrm{mg} / \mathrm{dm} 2$, and by the $\mathrm{a} / \mathrm{b}$ ratio all hybrids had almost the same value of 2.4-2.5.

Electricity consumption was $433 \mathrm{~kW}$ during the period from March 12 to April 30, the average consumption at ten-hour lighting was $9 \mathrm{~kW} /$ day.

Cucumber seedlings should be kept under LED lamps when they are located at a height of $1.0 \mathrm{~m}$ from the shelf in the industrial cultivation under conditions of complete substitution of natural light for artificial light. Too high temperature will be in the plant area at a lower lamp location. This has a negative effect on plant growth.

Supplementary light mode is BV700+RV350+BF350+FRF350 during seedling growth, it is all to 500 after planting, but requires increasing illumination up to 10-20 thousand lux. The illumination varied at all to 700 mode between 5662 and 6944 lux in our experiments. 
You must control the microclimate, in particular the optimum temperature of the air and substrate during the day and night, the concentration of carbon dioxide in the supplementary light mode, and the humidity of the air, to obtain high yields.

The duration of the dark period of the day can be reduced by completely replacing natural light with artificial light. It should be at least 4 hours for cucumber plants according to literature data. We have proved that ten hours of supplementary lighting ensures the development of generative organs.

Supplemental lighting is required for better growth of the lower tiers of cucumber plants, because the location of the lamps above the rows cannot provide good light to the lower tier of plants. The plants gave more cucumber plants in the center.

\section{Conclusions}

Under photoculture conditions of growing cucumber with the experimental ESCO phytosystem based on narrowband light-emitting diodes, the following conclusions can be made:

1. The formation of generative organs of cucumber under supplementary lighting with narrow-band LEDs is good. This is confirmed by plants of hybrid Vyatsky. Female flowers were already formed in the first nodes under BV700+RV350+ BF350+FRF350 mode. Flowering came later in the plants grown in natural light by 7-14 days.

2. The average growth per hybrid was less in the absence of the RV mode during the period from March 20 to 25 than in the modes with the presence of RV. The length of internodes also decreased.

3. The dependence of stem length on the location under the lamps is traced. Plants located in the center between two lamps had a shorter length. The highest length was in the plant under the green lamps on the RMT hybrid. The plant length was longer under the white lamps on the Real Colonel and Vyatsky hybrids.

4. More cucumber fruit was harvested from the plants in the center between the lamps.

5. Defining the chlorophyll content showed its optimal amount and depended on the varietal characteristics of plants.

6. The best supplementary lighting mode is BV700+RV350+ BF350+FRF350 for cucumbers during the seedling growth period. Subsequently, the mode should be changed to all to 500 .

\section{References}

1. O. V. Avercheva, Yu. A. Berkovich, A. N. Erokhin, T. V. Zhigalova, S. I. Pogosyan, S. O. Smolyanina, Plant Physiology, 56 (2009)

2. E. M. Basarygina, O. G. Litzinger, T. A. Putilova, APK in Russia, 24 (2017)

3. Z. Bian, C. Lu, Q. Yang, R. Cheng, W. J Liu, Sci. Food Agric, 95 (2015)

A. Brazaitytėa, S. Sakalauskienėa, G. Samuolienè, J. Jankauskienėa, A. Viršilèa, A. Novičkovasb, R. Sirtautasa, J. Miliauskienėa, V. Vaštakaitėa, L. Dabašinskasb, P. Duchovskis, Food Chemistry, 175 (2015)

4. G.V. Efremova, V.A. Ponomarev, Agricultural Sciences, 6 (2016)

I. Fallstrom, G.M. Bochenek, Acta Hortic, 1134 (2016)

5. O.V. Ilyin, T.O. Ilyina, E.O. Seyamchkina, Vegetables of Russia, 2 (2009)

6. T. Groher, S. Röhlen-Schmittgen, A. Fiebig, G. Noga, M. Hunsche, Scientia Horticulturae, 250 (2019) 
7. E. De Keysera, E. Dhooghea, A. Christiaensb, M.-C.Van Labekec, J. Van, Huylenbroeck Scientia Horticulturae, 253 (2019)

8. A.E. Kohler, R.G. Lopez, Scientia Horticulturae, 281 (2021)

9. I.A. Kungs, I.A. Ugreninov, Herald of the Krasnoyarsk HAU, 3 (2015)

10. I.V. Kuryanova, S.I. Olonina, Bulletin of NGIEEI, 7 (2017)

11. S.S. Litvinov, Methodology of field experience in vegetable growing (2011)

12. Yu. C Martirosyan, A. A. Kosobryukhov, V. D. Kreslavsky, O. S. Melik-Sarkisov, Potato Growing, 13 (2007)

13. N.P. Myshenkov, V.A. Shuvaev, Gavrish, 3 (2010)

14. V. Seleznev, N. Mikheeva, Gavrish, 3 (2007)

15. A.V. Sokolov, O.A. Roshchin, S.A. Kachan, Innovations in agriculture, 2 (2017)

16. D. Sokoljanskaya, E. Blagorodova, Vegetable growing from theory to practice (2018)

17. O.R. Udalova, G.G. Panova, L.M. Anikina, Vegetables of Russia, 4 (2018)

18. J. Wang, S. Mao, Q. Wu, Y. Yuan, M. Liang, S. Wang, K. Huang, Q. Wu, Food Chemistry, 356 (2021) 